\title{
EL ESPAÑOL ES EL ÚNICO PUEBLO CAPAZ DE
}

\section{AUTODENIGRARSE}

\section{SPANISH IS THE ONLY PEOPLE CAPABLE OF SELF- DENIGRATION}

José Antonio Martínez Pons: Departamento de Química Analítica e Ingeniería Química. Universidad de Alcalá de Henares. Madrid (España) joseantonio.martines@uah.es

\section{CURRÍCULUM VITAE}

Licenciado en Ciencias Físicas (Geofísica) por la Universidad Complutense de Madrid (España) y en Ciencias Químicas (Química física) por la UNED (España). Doctor por la Universidad de Alcalá de Henares (España) en el año 2000. Profesor de la Universidad de Alcalá de Henares en el área de Química analítica e Ingeniería química.

\section{RESUMEN}

¿Por qué los españoles actuales nos avergonzamos de lo que hicieron los españoles en América y casi, o sin casi, pedimos perdón a los actuales hispanos si, a fin de cuentas, caso de cometerse barbaridades, quienes las cometieron fueron los antepasados de los americanos, no los nuestros que se quedaron en España? La respuesta a esta cuestión se intenta encontrar en este análisis. 


\title{
PALABRAS CLAVE
}

Españoles - Antepasados - Colonización

\section{ABSTRACT}

Why the current Spanish ashamed of what the Spanish did in America and nearly or almost no, we apologize to Hispanics if present, after all, if committed atrocities, who committed them were the ancestors of the American, not ours who stayed in Spain? The answer to this question is trying to find in this analysis.

\section{KEY WORDS}

Spanish - Ancestors - Colonization

\section{TEXTO:}

\section{Letrilla de Samaniego a Iriarte}

\author{
"Tus obras Tomás no son \\ ni buscadas ni leídas, \\ ni tendrán estimación \\ aunque sean prohibidas \\ por la Santa Inquisición".
}

Leyendo el editorial del último número de Vivat Academia recordé que, hace unos días, encontré una frase que decía: "el español es el único pueblo capaz de 
autodenigrarse". Era del historiador Jesús Pabón. Gran verdad. A la mente me viene un poemilla (cito de memoria)

Oyendo hablar a un hombre, fácil es

saber dónde vio nacer la luz del Sol.

Si os alaba su tierra, es un inglés,

si os habla más de Prusia, es un francés,

y, si os habla más mal de España, es español.

Encima añadimos, al complejo, la ignorancia y la credulidad a todo lo que viene de fuera. No voy a meterme, sin que sirva de precedente, en cómo se valoran los artículos publicados, sino que voy a ser más genérico, voy a poner algunos ejemplos entre los cientos que se me ocurren.

¿Por qué los españoles actuales nos avergonzamos de lo que hicieron los españoles en América y casi, o sin casi, pedimos perdón a los actuales hispanos si, a fin de cuentas, caso de cometerse barbaridades, quienes las cometieron fueron los antepasados de los americanos, no los nuestros que se quedaron en España? Por otra parte ¿Sabemos que a los pocos años de la conquista en América se construyeron catedrales y universidades y América produjo artistas de altísimo nivel y en todas las artes, empezando por el Inca Garcilaso o por sor Juana Inés de la Cruz? ¿Conocemos el capital humano que absorbió la colonización? En paralelo a un Lope de Aguirre (vasco, por cierto), había un Fray Junipero Serra (mallorquín). ¿Nos atrevemos a comparar la cantidad de aborígenes que quedan en nuestras antiguas colonias, con los que quedan en las colonias británicas? ¿Pensamos en las tiranías a que estaban sometidos muchos de los pueblos americanos cuando llegaron los españoles? ¿Sabemos que allí se practicaban los sacrificios humanos y hasta el canibalismo, incluso en sociedades tan avanzadas como la azteca, que dicho sea de paso, no conocía la rueda, pero si la guerra de captura de víctimas para sus dioses? ¿Somos 
tan crédulos que pensamos que América la conquistaron los españoles porque poseían armas de fuego y caballos? Efectivamente los conquistadores poseían arcabuces, pocos y que podrían asustar a un indio la primera vez que los escuchara, pero a la segunda se daría cuenta de su escasa eficacia militar. En el siglo XVII el mosquetero disponía de 12 cargas, los doce apóstoles las llamaban ¿Cuántas flechas ponía en el aire un indio mientras un español hacía un disparo? ¿Cuál era el alcance, la fiabilidad y la precisión de una de aquellas primitivas armas? Lo mismo habría que decir del caballo. Los indios rápidamente aprendieron a hacerse con él y un general americano llegó a decir que la mejor caballería del mundo eran los siux, supongo que para justificar la paliza que le dieron a Custer. Si al menos se hubiera tratado de elefantes.

Naturalmente, no se compara, en absoluto, con las conquistas de otros pueblos. Sin embargo, los ingleses -para los que el duque de Alba era un monstruo-, consideran a Drake y Morgan, por citar algunos tópicos, héroes nacionales, y no hablemos de los tópicos americanos, como David Croquet o Billy el Niño. Por cierto, EE UU se apropió manu militari o manu banditi de más de la mitad del territorio nacional de México.

También ignoramos que, en las guerras de independencia americana, los nativos, por regla general, estaban con la Corona, los que querían separarse, para mangonear más a sus anchas, como ocurrió, fueron los criollos. Finalmente, las últimas colonias perdidas no significaron la independencia de los filipinos y cubanos, pasaron a otro amo, los EE.UU., con algunas diferencias formales, por lo que hace a los segundos.

Nadie parece preguntarse sobre las barbaridades sufridas por los propios españoles, católicos incluidos, en sus propias carnes y en sus propias tierras, dadas las condiciones sociopolíticas de la época. Que muchos de los conquistadores fueron 
unos bárbaros, nadie lo duda, pero también lo eran los nobles y gobernantes de entonces, no sólo españoles, sino de cualquier otra región del globo.

Otra sarta de sandeces son las que se escuchan sobre la Inquisición, para ser precisos, la "Santa Inquisición" y de rebote, contra la Iglesia Católica. Para empezar, todo el mundo cree a pies juntillas que se trata de un invento español, pues no señor, no es un invento español, es italiano y donde se desarrolló plenamente fue en Francia, aunque los frailes Dominicos tuvieran mucho que ver con ella. Mucho antes de su llegada a España, la Inquisición había actuado, por ejemplo, en Francia y valga el dato de la represión de los cátaros y, sobre todo, de los Templarios, donde la Inquisición actúa prácticamente como juguete de Felipe el Hermoso (el de Francia).

A pesar de todas las leyendas y de su fama de atormentadores, a lo largo de los tres siglos de actuación en España se cumplieron unas mil doscientas sentencias de muerte; sólo en la Inglaterra de Enrique VIII hubo más de tres mil ejecuciones, entre otras la de Ana Bolena, cuyo delito fue "alta traición", es decir ponerle los cuernos su Graciosa Majestad Henry VIII ¡Y lo que se ha contado sobre la historia de un pobre enfermo como era don Carlos, el hijo de Felipe II! La Inquisición no sólo entendía delitos de herejía, sino la mayoría de los cometidos por el clero, como simonía, vida escandalosa y también otros como la bigamia. La tortura era común en todos los tribunales europeos, no sólo de la Inquisición, y la justicia española no fue, ni mucho menos, la más salvaje. A Miguel de Servet, por ejemplo, no le quemó la Inquisición española, ni siquiera la católica, sino los calvinistas ginebrinos, bastante más intransigentes que los católicos. A Galileo le condenó la Inquisición italiana, a una pena de risa, en tiempos en que, por robar una gallina, se ahorcaba un hombre. Ya sé que el "tú más" no es un argumento pero, para juzgar un hecho, hay que ponerse en situación. A ver como juzgará la historia nuestra época... 
Si alguien se toma la molestia de leer muchos procesos, se encontrará con sorpresas, como la de aquel inquisidor que, cuando le presentaron a una bruja, prácticamente la mandó a dormir la mona. Es más, el pueblo no odiaba a la Inquisición, al menos al principio, con ellos no se metía, lo hacía con la gente importante y los jueces de la Inquisición eran mucho menos venales que los jueces civiles. ¿Cuál fue su pecado? Ser española, cuando a España se la temía, y ser la última y la que hizo más ruido.

¿Seguimos recordando sandeces? Nuestra relación con el Islam. Hemos pasado de hablar de la Reconquista como una gloria, a sentirla como una vergüenza. Primero ignoramos lo que pasaba en los reinos, reinitos y reinecillos musulmanes. Ignoramos que la invasión de Tarik y Muza fue la primera, si es que fue invasión, pero cada vez que los musulmanes ibéricos se relajaban, aparecían fundamentalistas del otro lado del estrecho a poner las cosas en orden (almohades, almorávides, benimerines...)

Luego vienen los problemas con la expulsión de los moriscos. Vamos a ver, los moriscos eran, o podían ser, una quinta columna a punto en caso de una invasión del turco o del berebere, se trataba de un peligro cierto e inminente. (Conviene recordar que los recientes atentados de Londres los cometieron personas que debían agradecer a Gran Bretaña muchas cosas, y no hablo de los cerebros de los atentados del 11 de marzo por no hacer conjeturas, pero cada día me surgen más dudas). Sólo pensar en lo que tenemos en España ahora, puede poner más de un pelo de punta, me temo que Europa vuelve a tener una quinta columna islámica dispuesta a todo.

Siguiendo en el tema, es fácil encontrar en Internet páginas, firmadas por ciudadanos españoles, en las que se pide al gobierno español que pida perdón por supuestos ataques con gases llevados a cabo en las guerras del Rif, hace por lo menos 75 años y naturalmente, que apoquine. Curiosamente, Ab del Krim nunca denunció estos ataques (que, es cierto, se produjeron) para no desmoralizar a los suyos (exactamente igual que ahora, ¿no?). Y, por otra parte, él intentó también comprar gases a 
traficantes europeos, que le estafaron. Naturalmente, no creo que nadie pida que Marruecos indemnice por las salvajadas de Annual o del Barranco del Lobo...

Olvidaba decir que, según nuestra insigne ministra de cultura, la que no sabe declinar el verbo dico, dicere, dixi, dictum, nada menos que Cervantes, vivió feliz en Argel. Mira que si llegan a saberlo los frailes que le rescataron, los maravedises que iban a haberse ahorrado...

Nuestra capacidad de autoflagelación llega a avergonzarnos de nuestra bandera hasta el punto de que izarla en ciertos lugares es provocación, no sólo en el Pais Vasco o Cataluña -perdón "Catalunya"- y respetarla es fascismo. Se llega extremos de ignorancia, como llamarla "monárquica", cuando la Primera República, tan república como la segunda, no la cambió. El otro día, no obstante, en pleno camino de Santiago, me tropecé con un grupo de peregrinos ciclistas con una "tricolore" italiana, la misma que tuvieron con la monarquía, incluso en los años del fascismo, de casi dos metros cuadrados, desplegada a todo viento. Ellos no se avergonzaban de ser italianos, fueran napolitanos, vénetos o florentinos, y su bandera, con menos historia que la nuestra, era la suya, la de todos los italianos.

¿No tendrían que pedirnos, a su vez, perdón todos aquellos pueblos que nos invadieron y/o conquistaron a lo largo de la historia? Podemos empezar por los fenicios y acabar con los franceses, por citar conquistas realizadas a fuego y sangre. A lo peor, muchas de las salvajadas por nosotros perpetradas las aprendimos de otros, en nuestra propia carne. Negar que la historia constituye un conjunto de barbaridades perpetradas por bárbaros que sólo buscaban beneficios personales, sería negar la evidencia experimental, pero pocos pueblos pueden estar orgullosos, como el español, de haber dado a la historia, además de bárbaros, gentes preocupadas por los derechos humanos, cuando esos derechos nadie pensaba que existieran. Quizás por eso, seamos los únicos con una persistente y aterradora 
leyenda negra. ¿Qué otros pueblos se atrevieron, sobre la marcha histórica del momento, a denunciar los desmanes cometidos por sus paisanos?

No quiero alargarme. Es evidente que, si alguien desea que España desaparezca, el camino lo tiene fácil: fomentar la vergüenza de ser español, y el terreno estará abonado, bastará con regar un poco la semilla y ver ofensas en todo, hasta en el fútbol.

Por supuesto, lo primero es deshacer nuestro patrimonio común más valioso, la lengua española, no sólo con la actitud cerril de ciertos personajes, y no hablo únicamente de Carod (o Pérez), sino de quienes pretenden resucitar la fabla aragonesa, el llionés, el panocho, el castúo -supongo que, a este paso, hasta el cebollarense de Abajo-. Divide ut vinceas, que dijo César (el de la hermosa cabellera, según su nombre). Sólo deseo que cuando España se desmorone en Republiquillas de Taifas, se haga a la checoeslovaca (por cierto, bastante arrepentidos de haberlo hecho) y no a la yugoeslava. Mucho me temo que tenemos más papeletas hacia esta última solución.

PS.- De intención, no he tocado la forma de tratar los acontecimientos entre 1931 y 1975, empezando por el tópico del páramo cultural. Esto da de sí da para mucho, pero no quiero hacerle el caldo gordo a según qué personajes.

Una anécdota para terminar del todo:

El año pasado, en el Teatro de la Zarzuela se puso en escena "El asombro de Damasco", de Pablo Luna. El montaje era fantástico, pero hay unos cuplés en los cuales un morito le canta a una morita:

"A la me, a la me..a la Meca 
te voy a llevar montada en camello."

Y para no ofender a los que ponen bombas, se cambió por

"A la haba, a la haba... a la Habana

te voy a llevar montada en camello."

Ni siquiera, los veladores de las buenas formas tuvieron imaginación para cambiar "montada en camello" por "haciendo un crucero", lo que al menos tendría sentido. 